\title{
HIGH CURRENT DENSITY CATHODES
}

\section{G. Thornber}

Spectra-Mat, Incorporated

Prepared for:

Army Electronics Command

April 1974

DISTRIBUTED BY:

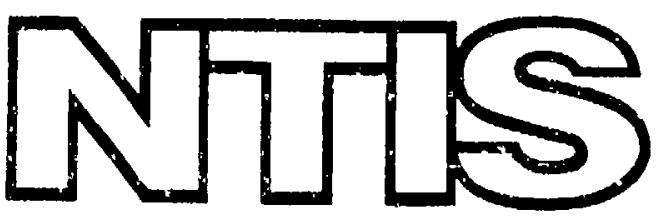

National Technical Information Service U. S. DEPARTMENT OF COMMERCE 


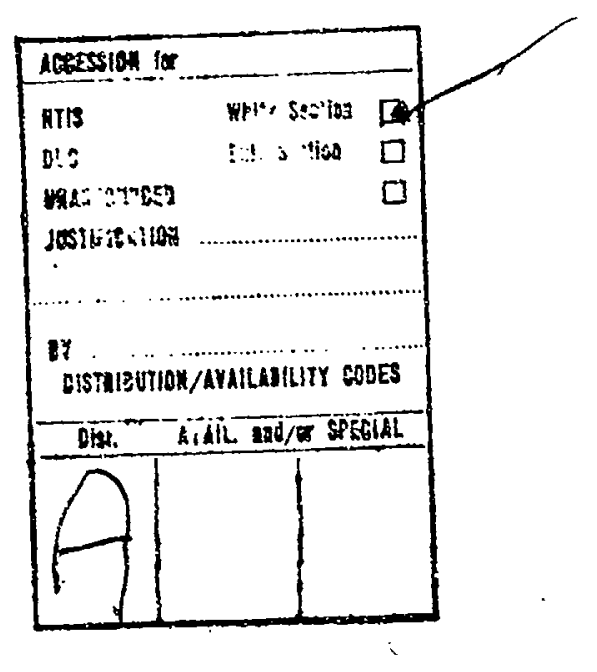

\section{NOTICES}

\section{Discloimers}

The findings in this report are nat to be cunstrued as an official Department of the Army positiou, unless so designated by other authorized documenis.

The citation oi trade names and rames of manufectirers in this report is not to be construed as official Government indorsement or approval of commersial products or services referenced horein.

\section{Disposition}

Destroy this report when it is no longer needed. Do not return it to the originator. 
UNCTASSTFTED

SEGURITY CLASSIFICATION OF THIS PAGE (When Date Entorod)

\begin{tabular}{|c|c|}
\hline REPORT DOCUMENTATION PAGE & $\begin{array}{l}\text { READ INSTRUCTIONS } \\
\text { BEFORE COMPLETING FORM }\end{array}$ \\
\hline 2. GOVT ACCESSION NO. & 3. RECIPIENT'S CATALOG NUMBER \\
\hline \multirow{2}{*}{ High Current Density Cathode } & $\begin{array}{l}\text { 5. TYFE OF REPORT \& PERIOD COVERED } \\
\text { Semi-AnnuR1 } \\
1 \text { July } 1973-31 \text { DeC } 73\end{array}$ \\
\hline & 6. PERFORMING ORG. REPORT NUMBER \\
\hline 7. $A U T M^{\prime} \cdot R(s)$ & $\begin{array}{l}\text { 8. CONTRACT OR GRANT NUMBER(S) } \\
\text { DAABO7-73-C-0262 }\end{array}$ \\
\hline $\begin{array}{l}\text { 3. PERF'IIMING ORGANIZATION NAME AND AODRESS } \\
\text { Spectra-Mat Inc. } \\
\text { i2l o Highway One } \\
\text { Watsonville, CA } 95056\end{array}$ & $\begin{array}{l}\text { 10. PROGRAM ELEMENT,PROJECT. TASK } \\
\text { AREA A WORX UNIT NUMEERS } \\
62705 \text { A } \\
15762705 \text { A } 0550132\end{array}$ \\
\hline \multirow{2}{*}{$\begin{array}{l}\text { 11. CONTROLLING OFFICE NAME AND ADDRESS } \\
\text { US Army Electronics Command } \\
\text { Electronics Technology \& Devices Laboratory } \\
\text { Fort MOnmouth, NeW Jersey } 07703 \\
\text { 14. MONITORING AGENCY NAME \& ADDFESS(if diffofent from Controlling Office) }\end{array}$} & $\begin{array}{l}\text { 12. REPORT DATE } \\
\text { ApriI } 1974\end{array}$ \\
\hline & 13. NUMBER OF PAGES \\
\hline \multirow[t]{2}{*}{ 14. MONITORING AGENCY NAME Q ADDFESS (if diffetent from Controlling Office) } & $\begin{array}{l}\text { 15. SECURITY CLASS. (of thio roport) } \\
\text { Unclassified }\end{array}$ \\
\hline & $\begin{array}{l}\text { 15a. DECLASSIFICATION/DOWNGRADING } \\
\text { SCHEDULE CATION }\end{array}$ \\
\hline \multicolumn{2}{|l|}{$\begin{array}{l}\text { 16. DISTRIBUTION STATEMENT iof this Ropoti) } \\
\text { Approved for public release; } \\
\text { Distribution unlimited. }\end{array}$} \\
\hline \multicolumn{2}{|l|}{ 17. DISTRIBUTION STATEMENT (of the abstract entered in Block 20, in dilferent from Ropoft) } \\
\hline \multicolumn{2}{|l|}{$\begin{array}{l}\text { 18. SUPPLEMENTARY NOTES } \\
\text { Raprodusos by } \\
\text { NATIONAL TECHNICAL } \\
\text { INFORMATION SERVICE } \\
\text { Us Doparmant of Commorso } \\
\text { Springsioldd, VA. 2215i }\end{array}$} \\
\hline \multicolumn{2}{|l|}{$\begin{array}{l}\text { 19. KEY WORDS (Continue on reverse side if necessary and identlly by bloch number) } \\
\text { Thermionic Emitters } \\
\text { Tungstate Cathode } \\
\text { High Current Density Cathode } \\
\text { Matrix Cathode }\end{array}$} \\
\hline \multicolumn{2}{|c|}{ 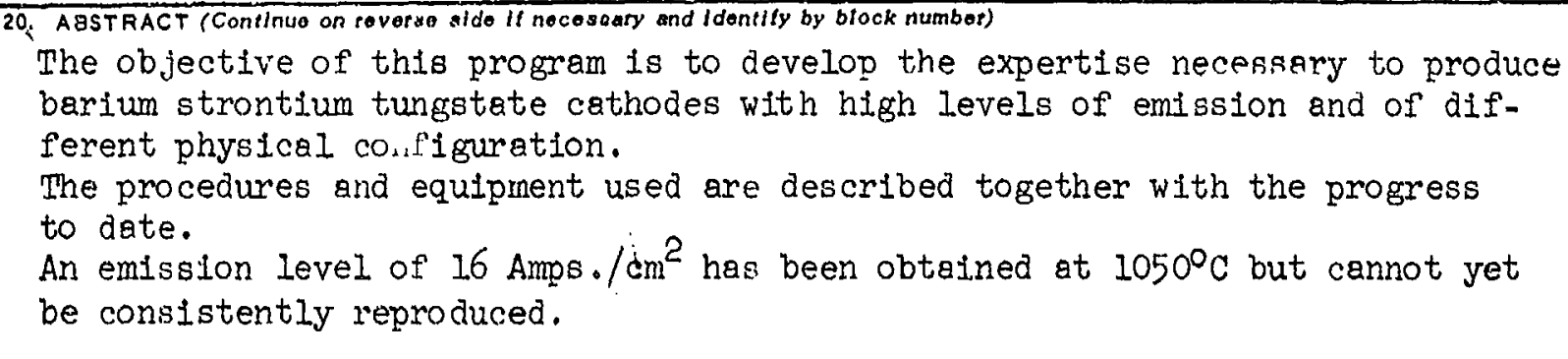 } \\
\hline
\end{tabular}

DD, FORM 1473 EUTTION OF I NOV $6 B$ IS OBSOLETE.

UNCLASSIFIED

SECURITY CLASSIFICATION OF THIS PAGE (Whon Dale Entorod) 
TR ECOM-0262.1

April 1974
Reports Control Symbol OSD 1366

\title{
HIGH CURRENT DENSITY CATHODES
}

1st Semi-Annual Report

I July 1973 to 31 December 1973

CONTRACT NO. DAAB07-73-C.0262

DA Project No. IS7 62705A 0550132

\begin{abstract}
DISTRIBUTION STATEMENT
Approved for public release,

distribution unlimited.
\end{abstract}

\section{Prepared by}

\section{G. Thornber}

Spectra-Mat, Inc.,

1240, Highway One

Watsonville, California 95076

For 
Page No.

1. Abstract

1

2. Objectives

2

3. Equipment 3

4. Cathode Fabrication 8

5. Conclusions 11

6. Manufacturing Procedures 13 


\section{ILLUSTRATIONS}

Figure No.

1

2

3

4

5
Title

High Temperature Air Furnace

High Temperature Dry Hydrogen Furnace

Water Cooled Diode

Cathode/Heater Assembly

Emission Plot - Activation
Page No.

4

6

7

9

12 


\begin{abstract}
The objective of this program is to develop the expertise necessary to produce barium figuration.

The procedures and equipment used are described together with the progress to-date. An emission level of $16 \mathrm{Amps} . / \mathrm{cm}^{2}$ has been obtained at $1050^{\circ} \mathrm{C}$ but cannot yet be con-
sistently reproduced.
\end{abstract}




\section{OBJECTIVES}

It is the objective of this study to develop the necessary expertise to fabricate and supply to USAECOM high current density tungstate cathodes as follows:

a. Strip beam cathode 0.060 inches long, 0.800 inches wide capable of delivering $8 \mathrm{~A} / \mathrm{cm}^{2}$ at a temperature of $1000^{\circ} \mathrm{O}$ and a life objective in excess of 6000 hours.

b. Planar cathode approximately 0.3125 inches in lelgth with a diameter of 0.106 inches for an emission objective of $16 \mathrm{~A} / \mathrm{cm}^{2}$ at an operating temperature of $1075^{\circ} \mathrm{C}_{\mathrm{t}}$ and a life objective in excess of 1000 hours.

c. Convergent calhode approximately 0.140 inches in diameter with a radius of curvature for 2 to 1 convergence and emission capability of $9 \mathrm{~A} / \mathrm{cm}^{2}$ at an operating temperature of $1025^{\circ} \mathrm{C}$ and a life objective in excess of 5000 hours.

d. Cylindrical cathode 0.025 inches in length and 1.200 inches in diameter for an emission objective of $8 \Lambda / \mathrm{cm}^{2}$ at an operating temperature of $1000^{\circ} \mathrm{C}_{t}$ and a life objectlve in excess of 6000 hours. Emission from this cathode $1 \mathrm{~s}$ to be from the cylindrical surface area excluding end caps.

The above cathodes must be capable of meeting the emlssion objectives cited at the speciffed temperature. This capability has been demonstrated in plamar tungstate cathodes devaloped on Government Contract DA28-043 AMC 02289(E) titled "High Current Density Cathodes". 


\section{EQUIPMENT}

At the beginning of this program it was decided that to avoid contamination problems some special pieces of equipment should be constructed and used only for processing these cathodes and materials.

This equipment included the following:

1. A tungsten ball mill. Although a molyhdenum ball mill had been used in the earlier program, poisoning of active cathodes by molybdenum had been recorded, In vlew of the fact that the greater part of the finished cathode is made from tungsten powder, this new ball mill could be expected to be an advantage.

2. An alr firing furnace with a horizontal alumina tuining allowing the sliding in and out of alumina boats. Both tubing and boats were to be of high purity alumina. The heating element for this furnace was quoted for delivery in four months. On arrival it was fitted into the insulating briok and support structure and hented by alternating current supplied by a transformer. The power was that recommended by the manufacturers of the heating element but the design temperature of $1450^{\circ} \mathrm{C}$ was not roached.

In fact the furnace temperature did not quite reach $1000^{\circ} \mathrm{C}$. The form of construction used is shown in figure (1) with porous alumina brieks forming the major portlon of the surrounding thermal insulation. The honting element has a resistance of approximately one ohm and, consoquently, has to be supplied by a transformer.

To reach the requiled temperature it was deolded to supply twice the recommonded input power and now transforiners wore procured. At this point over $3 \mathrm{kll}$ was being supplied to the heating element but the operating temperature was still too low. At thls stage advice was sought from the manufacturer's engineering staff.

3. Beonuse of the four month delivery quoted for the heathre clement a temporary alr firing furnace had to be constructed in order to allow the program to proceed.

This conststed of a hollow graphite cructble heated in air by a $10 \mathrm{~kW}$ induction heater and contalning an upright alumina cruelble. In this manner, a tomperature of just over $1400^{\circ} \mathrm{C}$ was readly obtained and samples of tungstate powder were prepared. Durlag the two hour firtug the graphite cruelble was almose compietely consumed, a flame burning from the top of it all the time. Thls was productuy carbon dloxide etc., and was presumably not strictly in ale firing nromess. Firings were also carrled out using a platinum cruclble instead of the alumina one, but this gave a pink woloration to the fired $\mathrm{mlx}$. 


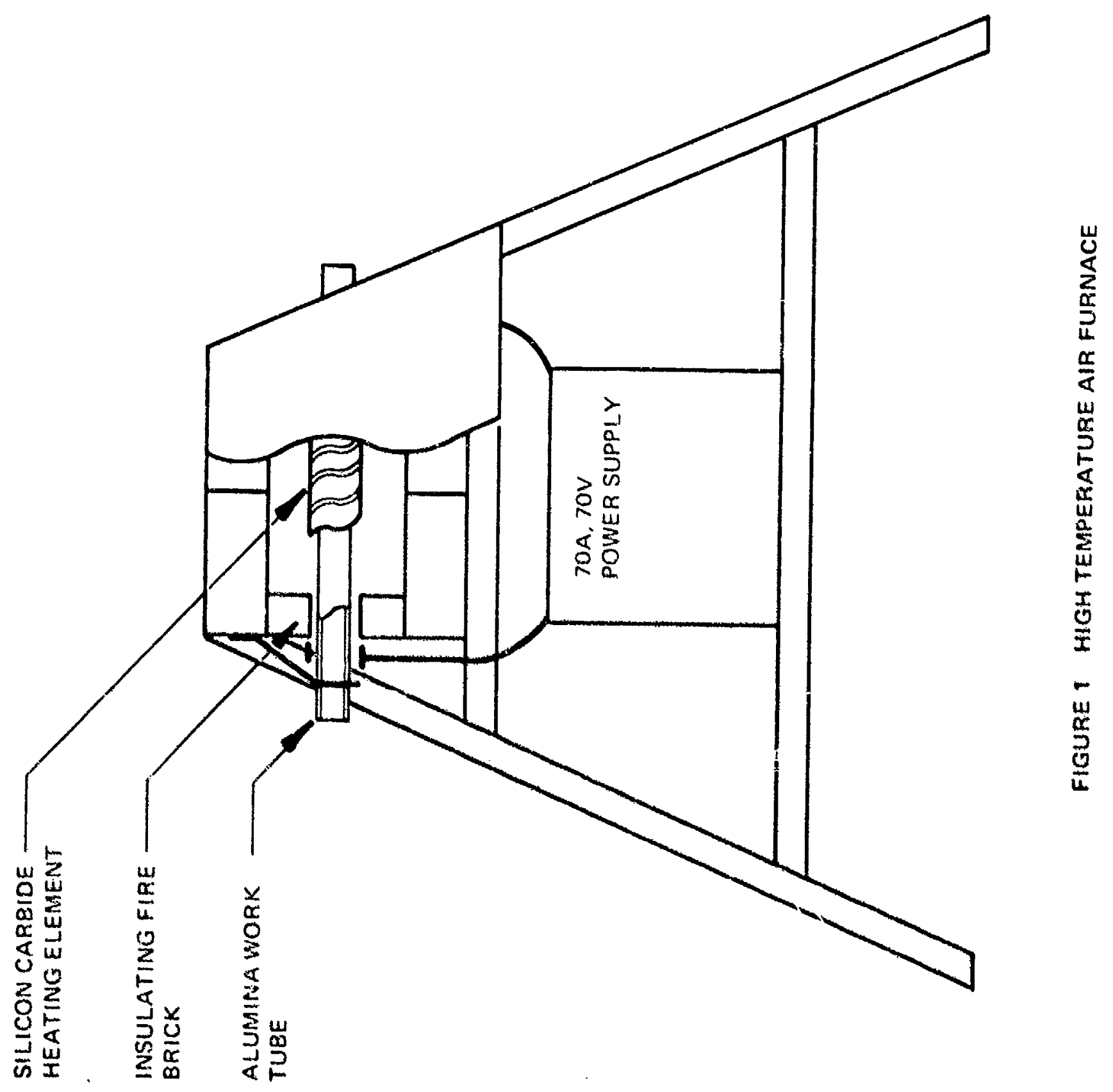

5 
4. A special furnace chamber was built for the hydrogen firing at $1840^{\circ} \mathrm{C}$. This consisted of a molybdenum cylinder as shown in figure (2). The whole assembly is placed inside a resistive heating eleme it made from molybdenum rod which is inside multiple heat shields. A line of sight to the inside of the molybdenum cylinder is prcvided to allow for optical pyrometer measure..ents of temperature. The hydrogen is passed through a catalytic unit converting any oxygen to water which is removed by a dryer. It has been standard practice to run through a heat cycle immediately before firing a cathode.

5. The demountable test diode is shown in figure (3). It consists of two cathode supports, the exhaust tubulation and water cooled anode brazed to the base with coppergold alloy and a cuver with a sapphire viewing window.

The use of silver and glass has been deliberately avolded to reduce contamination. Mounting of the cathode is accomplished by welding three rlienium wires to the main support plate which is rigidly held by the two threaded support rods. An anode to cathode spacing of 0.005 " to 0.007 " is held and the two faces are set parallel to each other.

All pumplng is carried out on a $50 \mathrm{l} / \mathrm{sec}$. Vac-ion pump with initial pump-down by a mechanical ofi pump thro'tgh a balieable trap.

6. In order to measure subllmation ratus s Sloan Model 200 lnetrument was purchased and the deteo.ing head oun be mounted on an alternative cover flted to the test diode with the cathole th an inverted postion. 


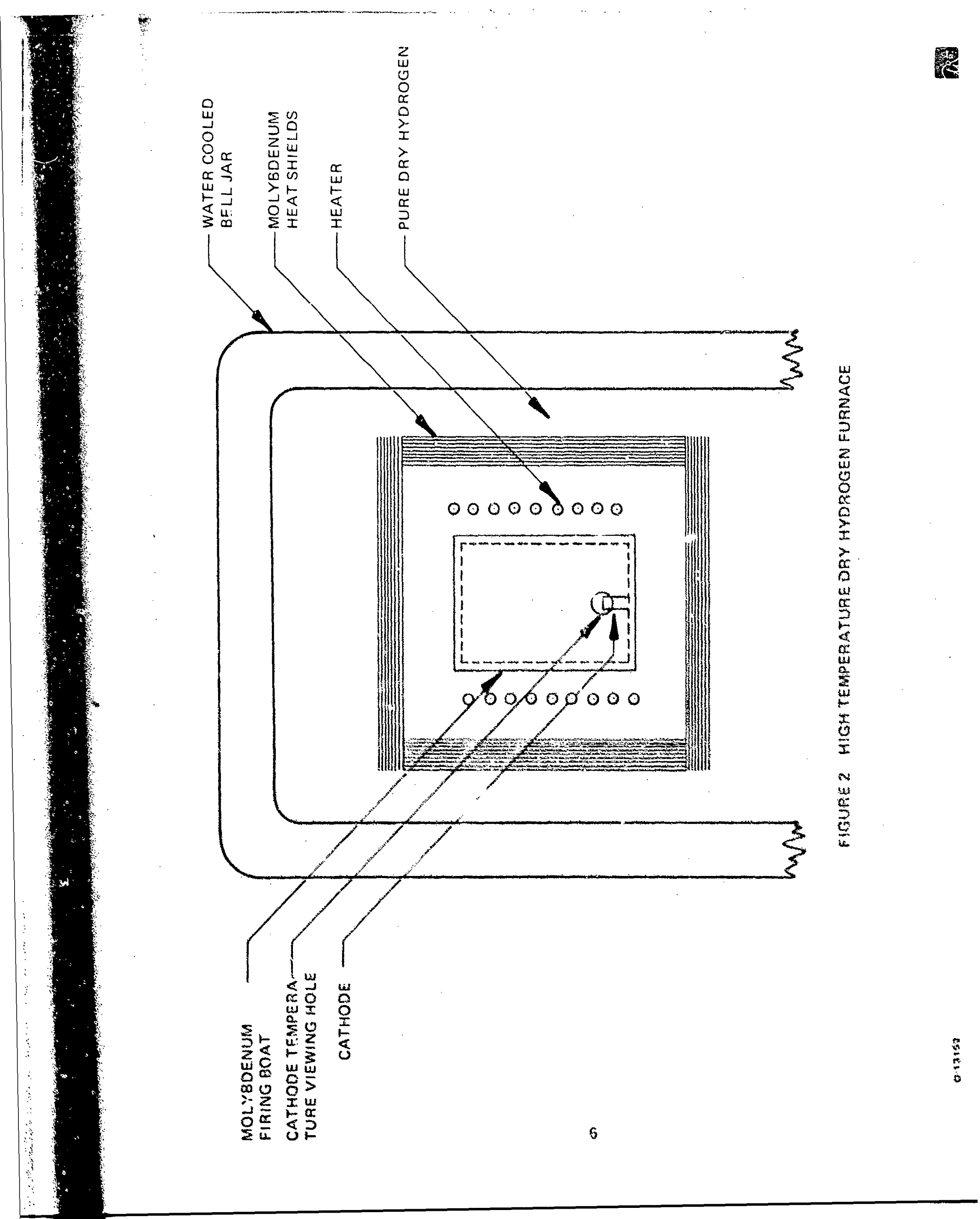




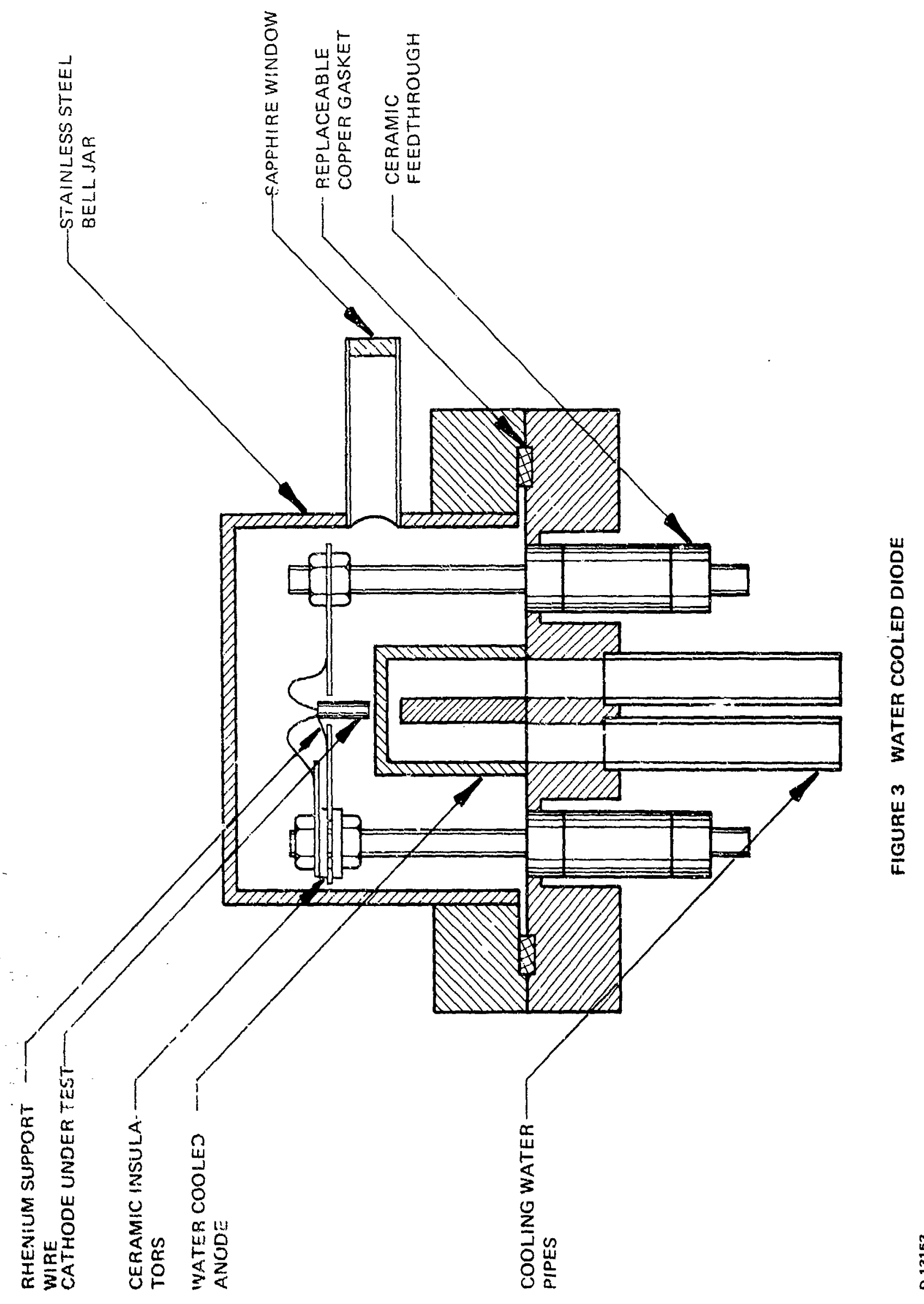




\section{CATHODE FABRICATION}

The dimensions of the cathodes fabricated to demonstrate basic emission performance are shown in figure (4). Emission is from the flat circular end of $0.106^{\prime \prime}$ in diameter. Tungsten heaters are specially wound and cataphoretically coated with a commerical alumina coating which is then fired on in wet hydrogen.

The first heater gave trouble and the method of support was mocifiled to remove the physical strain on the aiumina coating. Since then no heater problems have been encountereci.

Fabrication if the cathodes was according to the attached list of procedures with the following ad: i... l detalls:

It is important to carefully control both the temperature and time during the sintering operation, Inadequate firing can usually be detected during the subsequent machining operation because of the low mechanical strength of the cathode pellet. Firing for too long or at too high a temperature can result in an excessive loss of barium and a short life for the finished cathode.

The control of the $1840^{\circ} \mathrm{C}$ sintering temperature has been more difficult than expected owing to the uncertainties of the method of measurement. The calibration of the optical pyrometer had to be carried out three separate times and was finally checked against the melting points of known elements and alloys before being acceptable.

During the preparation of the pellet it is important that the pressing tool has short unsupported lengths. At the compaction pressure of 90 tons per square inch, small diameter rods which were unsupported repeatedly fractured. After reducing the unsupported length of the main compacting rod no further fracturing occured. However, some cathodes were built and were unsatisfactory in various respects. It turned out that these had been insufficiently compacted owing to a restriction in the movement of the compacting die. Further modification resulted in compaction which was satisfactory and did not cause any fracturing after repeated use.

The finishing of the emissive surface is done by carefully machining with a carbide tipped tool as described in the procedures. It is important to use a sharp tool and a slow feed. This very slow feed was produced by a geared brush type motor controlled by an electronic speed controller. A speclal cross-slide with the drive permanently attached was always used and various combinations of depth of cut and rate of feed are readily obtained with this arrangement. At the present time the adequacy of the 


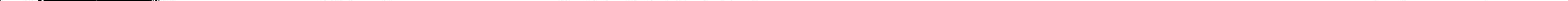


machining operation is judged by the optical appearance of the surface as seen through a binocular microscope. This is felt to be inherently unsatisfactory for continued cathode production and improved methods are being investigated. For instance a metallurgical microscope is being tried with photographs used as a permanent record for comparison of emission performance and surface detail. 


\section{CONCLUSIONS}

The results so far obtained have at times been promising, but, on the whole, have to be regarded as unsatisfactory.

An early cathode had the current-voltage diode characteristics as shown in figure (5). This data is plotted on "two-thirds" paper and 16 Amps. per $\mathrm{cm}^{2}$ corresponds to $911 \mathrm{~mA}$.

The activation process appeared normal, consisting of ten minutes at $1200^{\circ} \mathrm{C}$. , followed by tens of hours of further aging at a lower temperature whilst drawing current. After operation for a few days emission generally fell off, but this is attributed to the test diode still being connected to the main pumping station and thus exposed to various sources of contamination and higher pressure because of the long exhaust tubulation.

Further attemps to repeat and, hopefully, to improve these early results were unsuccesful. Every step of the procedures was checked many times and various problem areas were were discovered and the appropriate corrections made. Even after these corrections it was not possible to meet the emission requirements with subsequently fabricated cathodes.

In an attempt to obtain the required emission levels, emphasis is to be placed in three areas:

1. Completion of the air furnace.

2. Improved purification of the hydrogen.

3. Better definition and measurement of the machining operation. 


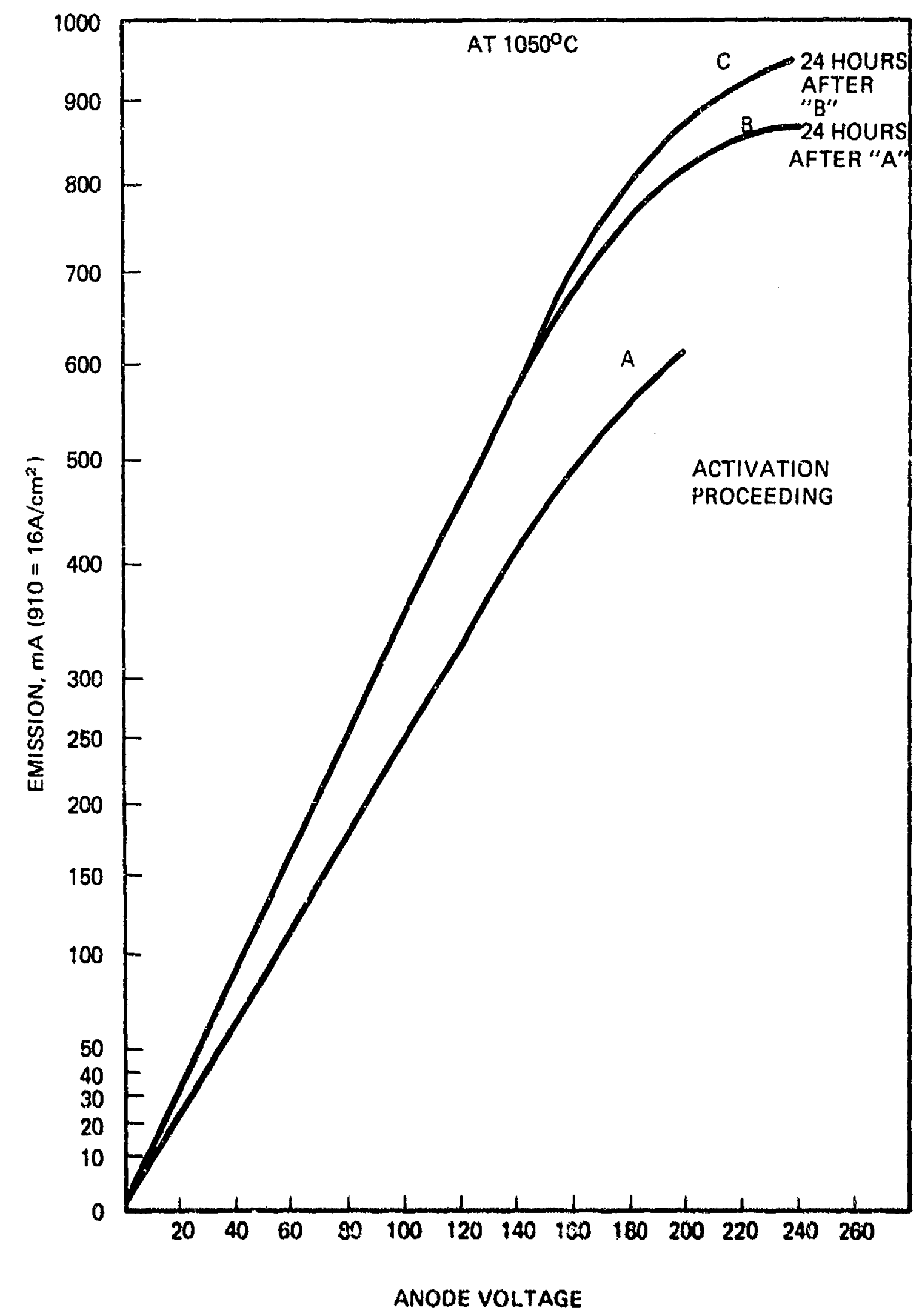

FIGURE 5 EMISSION PLOT - ACTIVATION

0.13166 


\section{PROCEDURES FOR THE MANUFACTURE OF}

\section{BARIUM TUNGSTATE CATHODES}

\section{PREPARATION OF ACTIVATOR COMPOUND}

a. Use stoichiometric quantities of $\mathrm{BaCO}_{3}, \mathrm{SrCO}_{3}$ and $\mathrm{WO}_{3}$ :-

$\begin{array}{lc}\mathrm{BaCO}_{3} & 18.5 \mathrm{lg} . \\ \mathrm{SrCO}_{3} & 2.76 \mathrm{~g} . \\ \mathrm{WO}_{3} & 8.73 \mathrm{~g} . \\ \text { Methanol } & 75 \text { c.c. }\end{array}$

b. Ball mill for 2 hours.

c. Filter the mixture using a fine Buchner funnel torming a cake.

d. Fire the cake in air at between $1400^{\circ} \mathrm{C}$ and $1450^{\circ} \mathrm{C}$ for two hours.

e. Grind dry in a mortar and soreen through a 325 mesh sleve.

f. Repeat (d) and (e) above. The powder produced is $\mathrm{Bag}_{5} \mathrm{Sr}\left(\mathrm{WO}_{6}\right)_{2}$.

2. PRE PARATION OF CATHODE PELLET

a. Dry ball mlll for 15 hours:-
1. $\mathrm{Bag}_{5} \mathrm{Sr}\left(\mathrm{WO}_{6}\right)_{2}-325$ mosh
$2.73 \mathrm{~g}$.
$9.14 w t . \%$
2. $\mathrm{ZrH}_{2}$
- 325 mesh
$0.36 \mathrm{~g}$.
$1.22 \mathrm{wt} .9$
3. Tungston
- 5 mloron powdor
$26.892 \mathrm{~g}$.
89.64wt.

b. Compact into oversized pellet at 90 tons per square tnoh using a press. Alivays uso a vibrator during this operation. 


\section{SINTERING THE CATHODE PE LLET}

a. Use an atmosphere of pure hydrogen passed through an oxygen removing unit and a condensing unit immersed in liquid nitrogen. Dry the condensing unit each time be-
fore use.

b. Raise the temperature slowily to $1500^{\circ} \mathrm{C}_{\mathrm{B}}$ and hold for five minutes.

c. Raise the temperature rapidly to $1840^{\circ} \mathrm{C} B$ and hold for $21 / 2$ minutes.

d. Allow to cool

4. MACHINING THE CA THODE PE LLET

a. Use sultably prepared Carboloy tool.

b. Use a rough cut of $0.005^{\prime \prime}$.

c. Use a second out of $0.002 "$.

d. Use a final cut of $0.00025 "$.

e. Use approximately 200 r.p.m.

t. Heat the cathede with a hot alr gun.

g. Photograph the surface using a metallurgtoal mloroscope at $X 700$ magnifleation. 